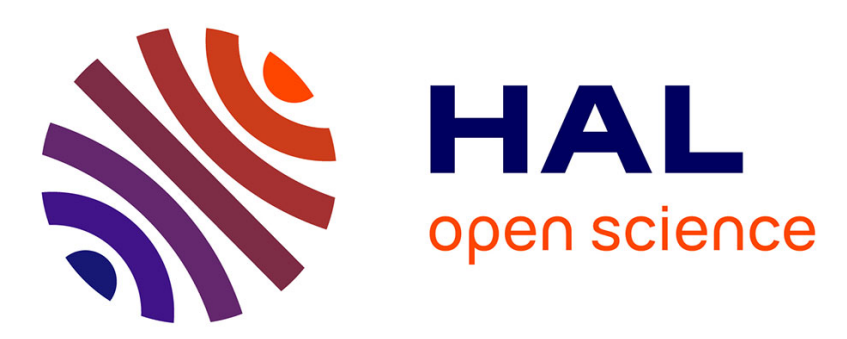

\title{
Quenching device for electrolytic aqueous solutions
} Adriaan-Alexander Ludl, Livia Eleonora Bove, Jiaqi Li, Marc Morand, Stefan Klotz

\section{To cite this version:}

Adriaan-Alexander Ludl, Livia Eleonora Bove, Jiaqi Li, Marc Morand, Stefan Klotz. Quenching device for electrolytic aqueous solutions. The European Physical Journal. Special Topics, 2017, 226 (5), pp.1051 - 1063. 10.1140/epjst/e2016-60244-8 . hal-01514921

\section{HAL Id: hal-01514921 \\ https://hal.sorbonne-universite.fr/hal-01514921}

Submitted on 3 May 2017

HAL is a multi-disciplinary open access archive for the deposit and dissemination of scientific research documents, whether they are published or not. The documents may come from teaching and research institutions in France or abroad, or from public or private research centers.
L'archive ouverte pluridisciplinaire HAL, est destinée au dépôt et à la diffusion de documents scientifiques de niveau recherche, publiés ou non, émanant des établissements d'enseignement et de recherche français ou étrangers, des laboratoires publics ou privés. 


\title{
Quenching device for electrolytic aqueous solutions
}

Adriaan-Alexander Ludl ${ }^{1, a}$, Livia Eleonora Bove ${ }^{1,2}$, Jiaqi Li ${ }^{1, b}$, Marc Morand ${ }^{1}$, and Stefan Klotz ${ }^{1, c}$

1 Institut de minéralogie, de physique des matériaux et de cosmochimie, Université Pierre et Marie Curie, CNRS UMR 7590, Sorbonne Universités, Paris, France

2 EPSL, Institute of Condensed Matter Physics, EPFL, 1015 Lausanne, Switzerland

Received 19 August 2016 / Received in final form 14 October 2016 Published online 18 April 2017

\begin{abstract}
A simple device based on splat cooling to liquid nitrogen temperatures is presented. Its application to the amorphization of binary aqueous solutions by fast cooling is demonstrated. The fraction of amorphous material obtained is $90 \%$ in eutectic solutions. Diffraction patterns of the vitrified solutions are presented and discussed.
\end{abstract}

\section{Introduction}

\subsection{Amorphizing solutions}

Glassy solutions of salts in water have been studied for decades [1-5]. Many highly hygroscopic salts typically show a glass forming region [5]. In this region they typically show a good ability to form glasses when cooled. This is the case for LiCl-water solutions with concentration close to the eutectic $[1,6]$. The composition/temperature phase diagram of solutions, be they metal alloys or salts in water, usually exhibits a eutectic point (E), which is the point of lowest temperature at which the liquid is stable. If crystalline nucleation is slow enough, it is possible to super-cool the liquid below this point. For aqueous $\mathrm{LiCl}$ solutions this can be achieved by cooling bulk quantities even at moderate rates of $20 \mathrm{~K}$ per hour. Thereby a glassy state can be obtained. In reference [1] the change in glass transition temperature $\left(T_{g}\right)$ with concentration is compared for a number of different solutions, and they attempt to explain the difference in the behaviour of these solutions. We are not aware of a formula for the relation between $T_{g}$ and concentration that gives satisfactory results for the solutions studied here. However, formulas have been proposed for glass forming polymer solutions $[7,8]$.

Nevertheless, the $\mathrm{NaCl}$-water system could not be amorphized so far, as slow cooling leads to the crystallisation of either pure ice, salt or dihydrate. There is a claim

\footnotetext{
a e-mail: alexander.ludl@gmail.com, Present address: Departament d'FMC, Universitat de Barcelona, Av. Diagonal 645, 08028 Barcelona, Spain

b Present address: Laboratoire des sciences de l'ingénieur pour l'environnement, Université de La Rochelle, France

c e-mail: stefan.klotz@impmc.upmc.fr
} 
by [9] that concentrated aqueous solutions, including those of sodium chloride, have been amorphized by cooling rates as low as $60 \mathrm{~K} \mathrm{~s}^{-1}$. However, amorphization was not determined by diffraction, but by visual inspection of the transparency of the cooled droplet, by the method described in [10]. This is known to give inaccurate results when the sample is micro-crystalline [11]. Transparent samples are expected to be liquid or amorphous. However, this is known to give inaccurate results since the sample may appear transparent even though micro-crystals are present, as observed in diffraction experiments. If the size of crystallites is much smaller than the wavelength of visible light or if the indices of refraction of the amorphous and crystalline components are similar enough, then the drops may remain clear although diffraction experiments reveal the existence of a crystalline part [11].

The difficulty to obtain amorphous NaCl-water solutions, although striking compared to other solutions, seems more understandable given that pure water is even more difficult to amorphize (see Sect. 1.3). There has been an ongoing debate on the relation between the glass transition temperature, distinct phases of amorphous water and the structure of the deep supercooled state [12-14]. Water is a common substance with properties that seem unusual when compared to other pure substances [15]. In the following, we discuss the occurrence of amorphous ice and solutions, and how they can be produced in laboratory experiments.

\subsection{Occurence of amorphous water in nature}

Pure water is a "bad glass former", i.e. extreme cooling rates are required to amorphize it, and various techniques have been proposed to achieve this. In the next subsection we will briefly present the techniques which work for pure water and discuss whether they are suited for solutions.

Amorphous ice is likely the most common phase of water in interstellar space [16]. In the solar system, the total mass of all types of ices is expected to be about twice that of the rocky material [17]. Recent work has suggested that ice is expected to play a crucial role in the accretion process leading up to the formation of planet sized bodies [18-20]. It has been demonstrated in a numerical model that condensation of vapour is an efficient growth mode towards the formation of decimeter sized pebbles [21]. Thus crystalline and amorphous ices occur in heterogeneous extreme environments ranging from small particles to planetary bodies in protoplanetary disks surrounding young stars. The interaction of solid phases of water with other elements in these conditions ought be taken into account. Salts are an excellent probe to test this interaction, because they are naturally abundant and soluble in liquid water. The question whether ices can include ions ought to be addressed.

Water crystallizes into ice $\mathrm{I}_{h}$ when cooled below the freezing point at ambient pressure. Freezing involves formation of a critical crystal nucleus (nucleation) and its growth. The nucleus may be formed by homogeneous or heterogeneous nucleation. Homogeneous nucleation is the formation of nuclei without preferential nucleation sites. It occurs spontaneously at $T_{\text {hom }}=235 \mathrm{~K}=-38^{\circ} \mathrm{C}$ at $1 \mathrm{~atm}$. If minor impurities are present, heterogeneous nucleation occurs on their surface and water freezes at higher temperatures [22]. Since water cannot be supercooled below the homogeneous nucleation temperature, rapid cooling is necessary to prevent ice nucleation and obtain amorphous material.

\subsection{Techniques to obtain amorphous pure water and solutions}

The first technique used to amorphize pure water was vapour deposition which leads to the formation of a low density amorphous form called amorphous solid water. This 
phase is similar to the hyper-quenched glassy water obtained upon hyper-quenching liquid droplets with cooling rates larger than $10^{5} \mathrm{~K} / \mathrm{s}[23]$. Together these phases are called low density amorphous water (LDA). In this phase, the water molecules mostly retain their tetrahedral coordination [24]. This process is expected to occur in the mesosphere $(\approx 50$ to $100 \mathrm{~km}$ altitude), the coldest layer of the atmosphere, where temperatures can drop below $130 \mathrm{~K}[22,25]$. It is also common in outer space, where water is often observed in an amorphous form [16].

Pure water can also be amorphized by compression (to $\approx 1 \mathrm{GPa}$ ) of ice $\mathrm{I}_{h}$ at low temperature [26,27]. The unannealed phase thus obtained is a strained and unrelaxed high density amorphous (uHDA) form of solid water [14]. This can be relaxed by annealing to $\approx 125 \mathrm{~K}$ under pressure yielding the expanded HDA (eHDA) form. Upon annealing to about $115 \mathrm{~K}$ at ambient pressure, uHDA transforms to LDA [28, 29].

Nevertheless, in the case of viscous solutions these two techniques encounter difficulties. The first one, vapour deposition or epitaxy, is a rather slow technique in terms of the amount of sample produced and it cannot be used easily to form highly concentrated amorphous solutions of salts in water at a given concentration. The second one is unsuited because ice $\mathrm{I}_{h}$ expels salts upon crystallisation, thus a homogeneous crystalline precursor at ambient pressure cannot be produced [30]. Once phase separation of a solution reaches a macroscopic scale, for instance by crystallisation of ice $\mathrm{I}_{h}$ from the solution, mixing times become very long compared to the time scale of most experiments, because the diffusion of ions in the glass is very slow at low temperatures. Hence this technique is not suited to produce a glass with uniform distribution of ions.

Two techniques which are suitable to amorphize solutions are jet freezing of emulsions and splat-cooling. It has been shown that pure water and dilute solutions can be amorphized by jet freezing droplets in emulsion [31]. For the emulsion a liquid cryomedium such as n-heptane has to be used. This method has been used for solutions of $\mathrm{LiCl}[32]$. The main inconveniences are the difficulty to separate the sample from the cryomedium and to avoid crystallisation of the sample droplets in the process.

The technique used in this work is similar to the splat-cooling technique, which was originally developed for metals in the 1960s [33]. The group of Mayer at the University of Innsbruck (Austria) were the first to apply this approach to pure water and aqueous solutions [23]. This technique is based on the rapid cooling of droplets (called splat) on a solid substrate. The three possible regimes of splat cooling are ideal cooling, intermediate cooling and Newtonian cooling. The boundaries between these regimes are expressed in terms of the dimensionless Nusselt number, which is $\mathrm{Nu}=h s / K$, where $h$ is the heat transfer coefficient for the interface between splat and substrate, $s$ is the thickness of the splat layer and $K$ is the thermal conductivity of the splat.

In the first case, known as ideal cooling $(\mathrm{Nu} \rightarrow+\infty)$, the cooling rate is determined completely by the droplet's size and its thermal properties. In reference [33] it has been shown that for perfect contact $(h=+\infty)$ between splat and a semi-infinite substrate, whose density, specific heat and thermal conductivity are temperature independent, the cooling rate $(\dot{T})$, apart from constants for material properties, varies as $\dot{T} \propto z^{-2}, z$ being the distance from the interface. Hence larger cooling rates are achievable closer to the interface, this means that in thinner splat the minimum cooling rate will be larger.

Newtonian cooling is the opposite limiting case $\mathrm{Nu} \ll 1$, where the temperature gradient in the droplet is negligible and the cooling rate is determined entirely by the heat flow at the interface. Jones [33] refers to the region in between, where $\mathrm{Nu}$ is of the order of unity, as intermediate cooling. The Newtonian and ideal regime are illustrated in Figure 1. According to finite difference calculations by [34] for iron freezing on copper, Newtonian cooling prevails for $\mathrm{Nu}<0.015$, and ideal cooling for 


\section{Newtonian}

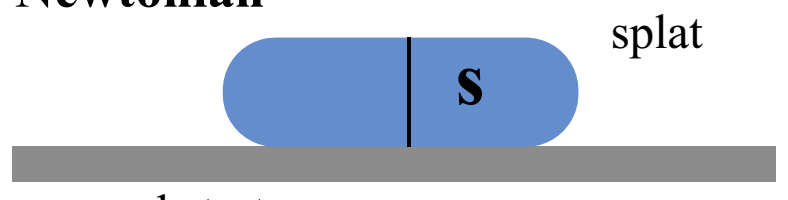

substrate

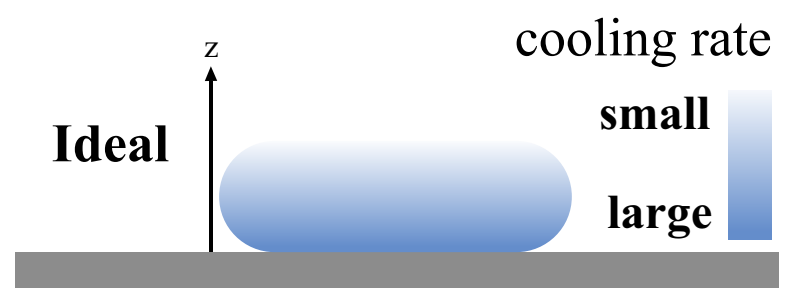

Fig. 1. The Newtonian and ideal cooling regimes of a droplet (splat) on a substrate during splat cooling.

$\mathrm{Nu}>30$. These calculations also show that for Newtonian cooling $\dot{T} \propto z^{-\alpha}$, where $\alpha \geqslant 1$ is a constant.

\section{Quenching procedure}

\subsection{Experimental set-up}

Our device for fast quenching is depicted in Figure 2 and a schematic identifying the parts is given in Figure 3. It exploits the rapid cooling of micrometer sized droplets on a pre-cooled solid substrate. The surface, on which droplets are projected, is a circular plate of an aluminium-copper alloy. This alloy was chosen for its high thermal conductivity $\left(K_{\mathrm{Du}} \approx 100 \mathrm{~W} / \mathrm{m} / \mathrm{K}\right.$ at $\left.80 \mathrm{~K}\right)$ to which the cooling rate of the sample is proportional [33]. The plate is placed inside a cylindrical vacuum chamber (diameter $330 \mathrm{~mm}$, height $200 \mathrm{~mm}$ ). The pressure inside is of the order of 1 mbar. The chamber is cooled by immersing its lower part in a liquid nitrogen bath. Cooling the device from room temperature $(300 \mathrm{~K})$ to $80 \mathrm{~K}$ takes about 1.5 hours. Moreover, the sample may be pre-cooled to $0^{\circ} \mathrm{C}$. This lowers the vapour pressure of the solution, thereby reducing evaporation in the vacuum and variations of the final concentration in the droplets.

The quenching proceeds in two steps: injection onto the plate and collection of the amorphous sample. Upon activation of the pneumatic valve, the sample solution is injected through a nozzle onto the cooled aluminium-copper plate. Commercial nozzles produced by Fluidics were used in our experiment. This type of nozzles is widely used for fuel burners and presents the advantage that for a given fluid (viscosity) and intake pressure, the flow rate has been calibrated. Also, the nozzles are available for a large range of viscosities, hence the quenching device can easily be adapted to the fluid to be splat-quenched. The flow rate through the nozzle at 80 bar is about $2.5 \mathrm{l} / \mathrm{h}$, and the velocity of the droplets can be estimated as $v=\sqrt{2 p / \rho} \approx 120 \mathrm{~m} / \mathrm{s}$. The cone of injection, depicted in Figure 3 by two lines surrounding the droplet, has an opening angle of $80^{\circ}$. A serious problem is corrosion, despite the fact that all materials in contact with the salty solutions are made of stainless steel. The device has to be cleaned after each use. To prevent corrosion the entire device was purged with pure water at least 4 times. The nozzle was removed, disassembled, and its parts rinsed in an ultrasonic bath in pure water, which was changed several times. 


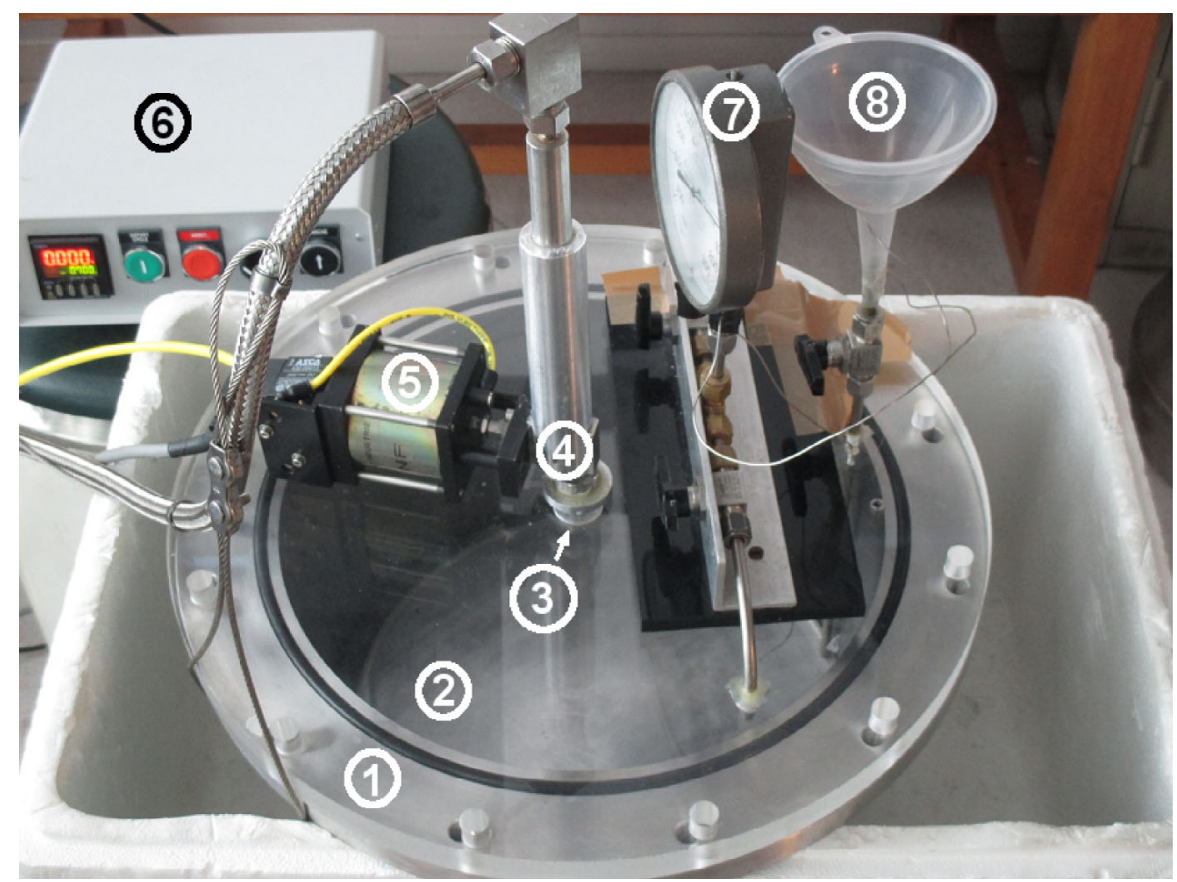

Fig. 2. Photography of the quenching device atop the container serving as liquid nitrogen bath. The parts are identified by numbers as: 1: vacuum chamber, 2: cryoplate, 3: nozzle, 4: valve, 5: actuator, 6: control unit, 7: manometer, 8: nitrogen funnel.

The pneumatic actuator is controlled by an electronic interface via an electronic actuator produced by Topindustrie (France). The system allows the operator to choose an injection time with a precision of $0.1 \mathrm{~s}$.

In order to collect the amorphous sample we proceeded carefully to guarantee that the sample remains close to liquid nitrogen temperature. The vacuum was broken by flooding liquid nitrogen into the chamber through a pipe connected to a funnel. This lead at first to a turbulent flow of solid nitrogen in the chamber. Small patches of sample were torn off the plate and formed a plaque, whose temperature may have risen higher than that of the powder sticking to the plate. This part was discarded. The rest of the sample was slowly immersed and remained at liquid nitrogen temperature. This part of the sample was reduced to fine powder, recovered under $\mathrm{N}_{2}$ vapour, collected in plastic containers filled with liquid nitrogen, and stored in dewars. Roughly $1 \mathrm{~g}$ of powder was produced in each quenching procedure.

Tests were performed varying four parameters in order to determine the conditions that allow to amorphise most of the sample for a given concentration and composition. These parameters are the injection pressure, the injection time, the pre-cooling temperature of the sample, and the surface roughness of the plate.

In our set-up, a pressure of up to 200 bar of helium gas was applied to the solution in the tube to drive it through the nozzle. Calibration experiments were performed to measure droplet size and amorphisation degree at different pressures. The droplet size was measured with an optical microscope on samples injected directly into liquid nitrogen. The result is shown in Figure 4, which shows that the droplet size decreases with applied pressure. The diameter of the droplets produced at 70 bar was measured to lie between 10 and $30 \mu \mathrm{m}$ (Fig. 4) with an average droplet size of about $20 \mu \mathrm{m}$. The average droplet size was estimated from photographs taken with an optical microscope through a glass plate onto the sample droplets in liquid nitrogen. The 


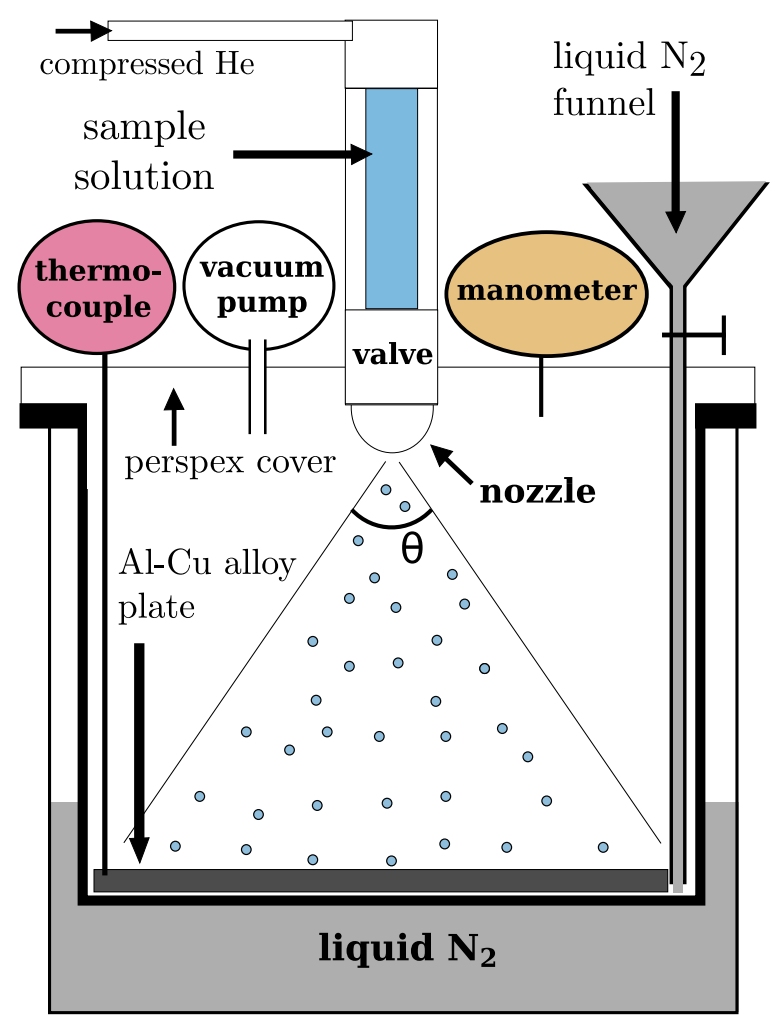

Fig. 3. Schematic of the quenching device. The sample solution in the tube above the nozzle is pre-cooled to about $0{ }^{\circ} \mathrm{C}$. The nozzle projects small droplets of diameter $\approx 10$ to $30 \mu \mathrm{m}$ onto the aluminium-copper plate at $80 \mathrm{~K}$, with a spraying angle $\theta \approx 80^{\circ}$.
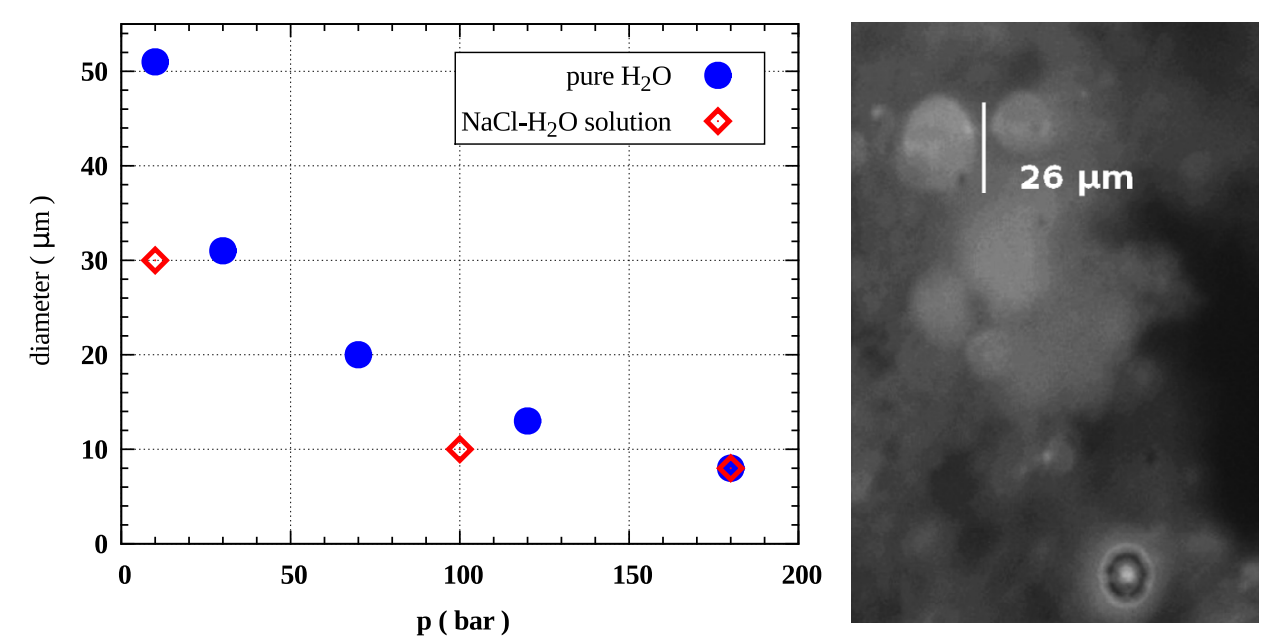

Fig. 4. Left: droplet size as a function of injection pressure for pure water (blue circles) and $\mathrm{NaCl}$ solution with $R=10.5$ (red diamonds). The molar ratio is defined in Section 2.2. The droplet size was measured on samples injected directly into liquid nitrogen. The width of the distribution of droplet sizes is about 5 or $10 \mu \mathrm{m}$. Right: photograph of the droplets produced at about 40 bar seen through an optical microscope. 
spread of the distribution of droplet sizes at a given pressure is 5 to $10 \mu \mathrm{m}$. Therefore it is reasonable to approximate the droplet size as about $20 \mu \mathrm{m}$ at $80 \mathrm{bar}$.

The injection time $t$ was also varied. Times from 0.5 to $3.0 \mathrm{~s}$ were tested. Since the amount of material injected is roughly proportional to the injection time, the latter controls also the thickness of the layer of splat. Thicker layers would cool more slowly and thus nucleation of ice can occur. Thinner layers yield less sample and are more difficult to collect. The injection time was chosen as a compromise between sample amount and cooling speed.

The largest fraction of amorphous material of $\mathrm{NaCl} \cdot 10.2 \mathrm{D}_{2} \mathrm{O}$ was obtained in conditions of 80 bar with $0.6 \mathrm{~s}$ injection time, on a surface roughened with sandpaper (grade P400, average particle diameter of $35 \mu \mathrm{m}$ ). For a droplet diameter of about $20 \mu \mathrm{m}$, the Nusselt number is $\approx 1$, hence we are in the intermediate regime of cooling. Using the data of [34] and [33], we estimate our cooling rate to be approximately $10^{4}$ to $10^{5} \mathrm{~K} \mathrm{~s}^{-1}$. Using another approach where $\dot{T}=\Delta T / \tau$, where the temperature difference for the droplet is $\Delta T \approx 200 \mathrm{~K}$, the characteristic cooling time is $\tau=s^{2} / D$, $s$ being the drop size and $D=1.2 \times 10^{-7} \mathrm{~m}^{2} / \mathrm{s}$ the thermal diffusivity of water at $25^{\circ} \mathrm{C}$, we obtain $\dot{T} \approx 6 \times 10^{4} \mathrm{~K} / \mathrm{s}$ which is consistent with the previous estimate.

\subsection{Preparation of the solution and powder}

Solutions of $\mathrm{NaCl}$ were prepared by dissolving salt in light or heavy water. For most X-ray diffraction experiments we used solutions in $\mathrm{H}_{2} \mathrm{O} . \mathrm{D}_{2} \mathrm{O}$ solutions were used for neutron scattering, because of the large incoherent scattering of $\mathrm{H}$. The $\mathrm{D}_{2} \mathrm{O}$ was at least $99.75 \%$ pure and $\mathrm{H}_{2} \mathrm{O}$ was filtered by a Millipore DirectQ. Its resistivity is greater than $18.2 \mathrm{M} \Omega \cdot \mathrm{cm}$ at $23^{\circ} \mathrm{C}$ (Grade 1 of the ISO 3696 standard). The concentrations are discussed in terms of the molar ratio $R=n$ (water) $/ n$ (salt).

For sodium chloride (rock salt) the stable eutectic concentration in $\mathrm{H}_{2} \mathrm{O}$ is $R=$ 10.7 close to the maximum solubility which is at $R=9.05$ at ambient temperature and atmospheric pressure. In $\mathrm{D}_{2} \mathrm{O}$ the solubility limit is 9.7 , our experiments indicate that the metastable eutectic is at 10.2. Solutions with $R$ in the range of 9.05 to 11 were produced to determine for which concentration the best amorphisation could be achieved. To ensure complete and homogeneous dissolution, all solutions were plunged for about ten minutes in an ultrasonic bath.

\section{Amorphous aqueous solutions}

The structure of amorphous samples obtained using the procedure described in the last section was studied by X-ray and neutron diffraction at low pressure $(p<1 \mathrm{~atm})$. First, we briefly describe the diffraction experiment. Second, we give an estimate of the fraction of amorphous material.

\subsection{Diffraction on amorphous samples}

In order to check the degree of amorphization, the samples were studied at ambient pressure by X-ray diffraction with a commercial X-PERT powder X-ray diffractometer at IMPMC, equipped with a low-temperature Anton Paar chamber. For samples intended for neutron diffraction experiments, a small amount of quenched solution was systematically recovered and measured as above by XRD. The sample was placed on a sample holder made of nickel plated copper, which was cooled to $\approx 80 \mathrm{~K}$. During transfer the temperature of the sample did not exceed $95 \mathrm{~K}$. This has been tested 


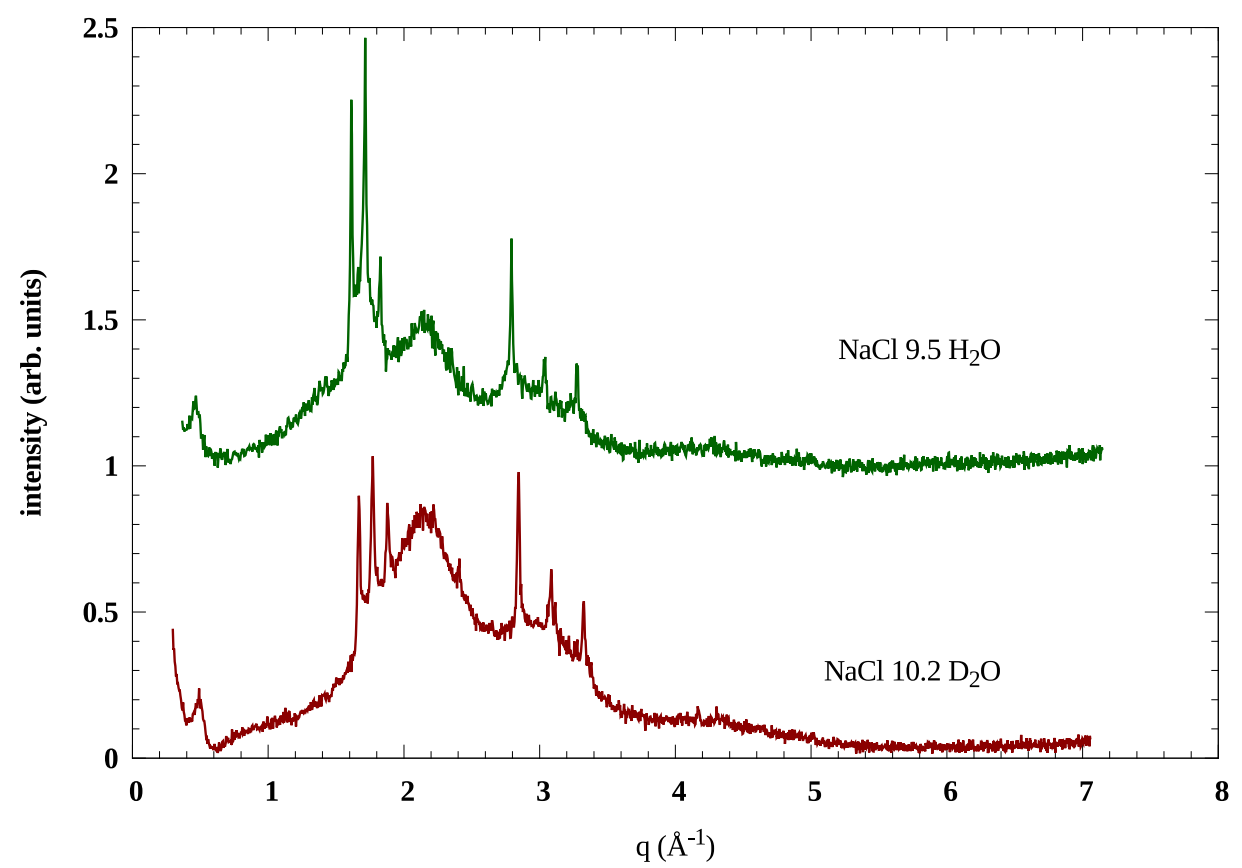

Fig. 5. X-ray diffraction patterns of quenched $\mathrm{NaCl} \cdot 10.2 \mathrm{D}_{2} \mathrm{O}$ and $\mathrm{NaCl} \cdot 9.5 \mathrm{H}_{2} \mathrm{O}$ at $80 \mathrm{~K}$ in the cryochamber. The samples were precooled to $\sim 0{ }^{\circ} \mathrm{C}$. They are the ones with the largest fraction of amorphous material.

using a mixture of iso-pentane and n-pentane which undergoes a glass transition for $T \approx 100 \mathrm{~K}$. The diffractometer uses $\mathrm{Cu} K \alpha$ radiation with an incident wavelength of $\lambda=1.5418 \AA$, set up in $\theta / 2 \theta$ geometry. The X-ray diffraction patterns of $\mathrm{NaCl}$ solution in $\mathrm{H}_{2} \mathrm{O}$ and $\mathrm{D}_{2} \mathrm{O}$ are shown in Figure 5 .

The neutron study was carried out on the high-intensity two-axis neutron diffractometer D20 [35] at the high-flux reactor of the Institut Laue-Langevin (ILL, Grenoble, France). The set-up is the same as that described in [36]. The monochromator was set to a wavelength of $1.87 \AA$ with average resolution of $\delta d / d=3 \cdot 10^{-3}$. A helium flow cryostat, pre-cooled at $80 \mathrm{~K}$ with a pressure of approximately $100 \mathrm{mbar}$ of helium exchange gas, was used as sample environment. The powder sample was loaded into a cylindrical vanadium cell of $6 \mathrm{~mm}$ diameter kept under liquid nitrogen. Three solutions of different concentrations close to the eutectic one were measured in this experiment. The diffraction data were normalised using the empty vanadium cell, empty cryostat, and vanadium standard measurements. In order to remove the background contribution from the cryostat and correct for detector efficiency, the data were reduced using the formula given in [36]. The neutron diffraction patterns of $\mathrm{NaCl}$ solution in $\mathrm{D}_{2} \mathrm{O}$ and of pure $\mathrm{D}_{2} \mathrm{O}$ ice $\mathrm{I}_{h}$ are shown in Figure 6 .

In order to identify the phases present in the samples, the diffraction patterns of the known crystalline phases of the system at ambient pressure were calculated with FullProf $[37,38]$. The structure data for ice $\mathrm{I}_{h}$ (hexagonal, space group $P 6_{3} / \mathrm{mmc}$ ) was taken from [39]. That of $\mathrm{NaCl}$ is face-centered cubic (space group $F m \overline{3} m$ ). The sodium chloride dihydrate structure (monoclinic, "probable" space group $P 2_{1} / c$ ) of [40] was used. 


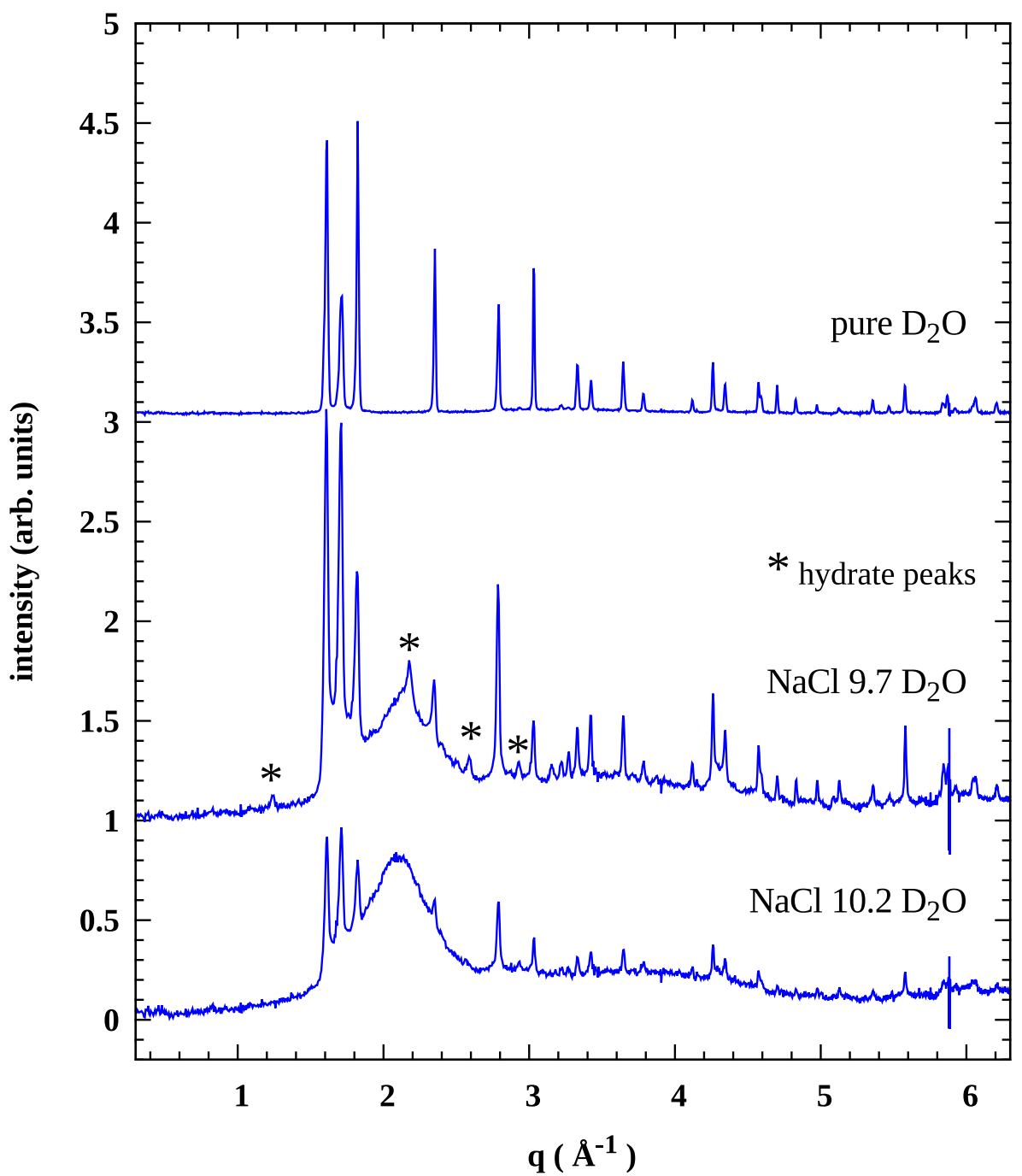

Fig. 6. Neutron diffraction patterns of quenched $\mathrm{NaCl} \cdot R \mathrm{D}_{2} \mathrm{O}$ and pure ice $\mathrm{I}_{h}$ (top) at $80 \mathrm{~K}$ measured on D20 at ILL. The composition is indicated on the right. During the measurement the pressure is that of the helium exchange gas $(\approx 100$ mbar $)$. The sample with $R=10.2$ contains more amorphous material with respect to the crystalline $\mathrm{I}_{h}$. Hydrate peaks appear in the pattern of the sample with $R=9.7$ but not in that with $R=10.2$. The first four clearly visible hydrate peaks are marked by asterisks.

\subsection{Fraction of amorphous material}

Figure 5 shows the X-ray diffraction patterns of samples which show the highest fraction of amorphous versus crystalline material. The first samples produced were obtained from NaCl- $\mathrm{H}_{2} \mathrm{O}$ solutions with compositions $R$ between 9 and 11 . This concentration range was chosen to bracket the stable eutectic concentration $(R=10.7)$. The samples with $9.5 \leq R \leq 9.8$ contained the largest fraction of amorphous material.

For $\mathrm{D}_{2} \mathrm{O}$ the solubility limit of $\mathrm{NaCl}$ is $R=9.7$ at room temperature and ambient pressure. Trials at different concentrations showed that the largest amorphous fraction could be obtained for $R=10.2$. This was confirmed in our experiment on 


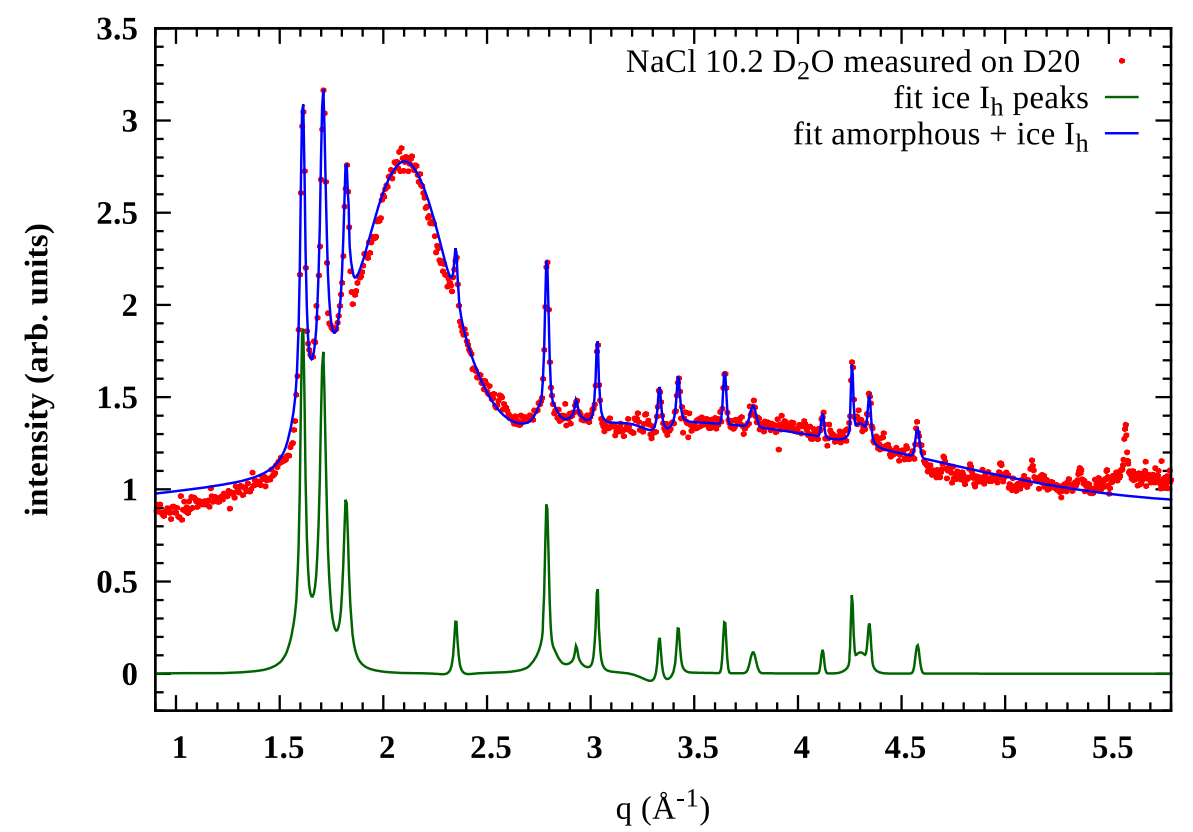

Fig. 7. Neutron diffraction pattern of $\mathrm{NaCl} \cdot 10 \cdot 2 \mathrm{D}_{2} \mathrm{O}$ measured on $\mathrm{D} 20$ at ILL [36] at 100 mbar (red points). The sum of the fits of amorphous and crystalline contributions is shown in blue on top of the data. The crystalline part is estimated to be about $8 \%$ of the sample material according to the fit of thirteen ice peaks with pseudo-Voigt profile functions, shown in green below the data.

$\mathrm{D}_{2} \mathrm{O}$ at ILL. Figure 6 shows the neutron diffraction patterns obtained for pure hexagonal ice of $\mathrm{D}_{2} \mathrm{O}$, for $\mathrm{NaCl} \cdot 9.7 \mathrm{D}_{2} \mathrm{O}$ and for $\mathrm{NaCl} \cdot 10.2 \mathrm{D}_{2} \mathrm{O}$. Although both salty samples contain amorphous material, a larger fraction is present in the sample with $R=10.2$. The sample with $R=9.7$ shows larger ice $\mathrm{I}_{h}$ peaks and also $\mathrm{NaCl}$ dihydrate peaks. The latter observation is coherent with the phase diagram of $\mathrm{NaCl}_{2} \mathrm{H}_{2} \mathrm{O}[41,42]$. The fact that $R=10.2$ solutions amorphise without forming dihydrate indicates that the rate of formation of the dihydrate at this concentration is slower than the quenching rate of our device.

From the above observations we conclude that the isotopic effect of substituting $\mathrm{D}$ for $\mathrm{H}$ in these solutions shifts the composition of best amorphisation from $R=9.5$ in $\mathrm{H}_{2} \mathrm{O}$ to $R=10.2$ in $\mathrm{D}_{2} \mathrm{O}$.

Figure 7 shows the neutron diffraction data of $\mathrm{NaCl} \cdot 10.2 \mathrm{D}_{2} \mathrm{O}$ at $90 \mathrm{~K}$ and a fit to the data. The data reveal both peaks of crystalline material and amorphous features of the solution. By comparison with FullProf simulations of ice $\mathrm{I}_{h}$ peaks, we conclude that all the peaks correspond to ice $\mathrm{I}_{h}$, although with some texture. Therefore thirteen of the ice peaks in the neutron data at $90 \mathrm{~K}$ were fitted individually with pseudo-Voigt profile functions using the least squares algorithm of GNUPLOT 4.6 [43]. The respective intensities were obtained by integrating the fit of the ice peaks and the structure factor of amorphous material. This gave amorphous and crystalline volume fractions of $92 \%$ and $8 \%$ respectively. The texture observed in the sample may introduce an error of few percent points to the estimate of the fraction of crystalline material in the sample. We estimate that the error on the fraction above is approximately $2 \%$. Hence at most $10 \%$ are expected to be crystalline, and at least $90 \%$ amorphous.

The neutron data provide evidence that the crystalline part forms during the hyper-quenching process since the measured ice peaks correspond to deuterated 
ice $\mathrm{I}_{h}$. This cannot be formed by condensation of water from a humid ambient atmosphere during loading of the sample, which would be $\mathrm{H}_{2} \mathrm{O}$ ice. This deuterated ice must have formed from the injected sample. It is possible that this part of the sample heated up when it detached from the plate when the vacuum was broken. Another explanation would be that the layer of sample formed after injection is not of uniform height. In the areas where the sample layer is thicker cooling may be slower thus allowing the nucleation of pure ice.

A few samples of pure water quenched with our device have been measured by $\mathrm{XRD}$. All of them were highly crystalline. This is consistent with the cooling rate estimated to be $\approx 10^{4} \mathrm{~K} \mathrm{~s}^{-1}$ (see Sect. 2.1) which is lower than the minimal cooling rate required to amorphise pure water $\left(\geq 10^{5} \mathrm{~K} \mathrm{~s}^{-1}\right)$.

We have found that concentrated $\mathrm{NaCl}$ solutions amorphise at ambient pressure in a high density structure similar to the HDA form of pure water $[36,44]$, in agreement with similar observations for $\mathrm{LiBr}$ and $\mathrm{LiCl}$ solutions $[45,46]$. The samples produced with this device have been used in high pressure neutron diffraction studies $[36,47]$.

\section{Conclusion}

The quenching technique described here allows to amorphise highly concentrated viscous solutions of $\mathrm{NaCl}$ in water with an estimated quench rate of $10^{4}$ to $10^{5} \mathrm{~K} \mathrm{~s}^{-1}$. The best amorphous samples were obtained for $R=9.5$ in $\mathrm{H}_{2} \mathrm{O}$ and 10.2 in $\mathrm{D}_{2} \mathrm{O}$. An amorphous content of $92 \%$ was obtained in $\mathrm{D}_{2} \mathrm{O}$.

This method may be applied to obtain amorphous forms of other aqueous solutions or solutions with viscosity and surface tension comparable to that of the NaCl-water solutions. We believe that the residual crystalline impurities are due to a small amount of large droplets which suffer slow cooling times, or a bad contact of some part of the projected sample to the cold-plate. With further investigation this device might be improved and applied to produce amorphous forms of other aqueous solutions which could not be produced so far in large quantities.

The construction and first tests of the quench device were part of an internship of Jiaqi Li (Polytech Paris Sud) carried out at IMPMC in 2012. S.K. thanks W. Winstermann (Steinen $\mathrm{GmbH}$ ) and Dr. C. Kinias (ergTOP-I.A.U) as well as J. Klotz for technical advice on fuel burners. The authors are grateful to R. Pick for comments and helpful discussions. This work was supported by French state funds managed by the ANR within the Blanc International programme PACS under reference ANR-13-IS04-0006-01 and the Investissements d'Avenir programme under reference ANR-11-IDEX-0004-02, within the framework of the Cluster of Excellence Matériaux Interfaces Surfaces Environnement (MATISSE) led by Sorbonne Universités.

\section{References}

1. C.A. Angell, E.J. Sare, J. Chem. Phys. 52, 1058 (1970)

2. C. Angell, E. Sare, Cryo-letters 1, 257 (1980)

3. O. Mishima, J. Chem. Phys. 123, 154506 (2005)

4. C.J. Tainter, L. Shi, J.L. Skinner, J. Chem. Phys. 140, 134503 (2014)

5. G. Vuillard, Ann. Chim (Paris) 2, 233 (1957)

6. A. Elarby-Aouizerat, J.F. Jal, C. Ferradou, J. Dupuy, P. Chieux, A. Wright, J. Phys. Chem. 87, 4170 (1983)

7. M. Gordon, J.S. Taylor, J. Appl. Chem. 2, 493 (1952)

8. W. Brostow, R. Chiu, I.M. Kalogeras, A. Vassilikou-Dova, Mat. Lett. 62, 3152 (2008)

9. M. Warkentin, J.P. Sethna, R.E. Thorne, Phys. Rev. Lett. 110, 015703 (2013) 
10. V. Berejnov, N.S. Husseini, O.A. Alsaied, R.E. Thorne, J. Appl. Crystallogr. 39, 244 (2006)

11. M. Allix, in Du verre au cristal: Nucléation, croissance et démixtion, de la recherche aux applications, edited by D.R. Neuville, L. Cormier, D. Caurant (EDP Sciences, Les Ulis, 2013), Chap. 17

12. C.A. Angell, Science 319, 582 (2008)

13. V. Velikov, S. Borick, C.A. Angell, Science 294, 2335 (2001)

14. T. Loerting, K. Winkel, M. Seidl, M. Bauer, C. Mitterdorfer, P.H. Handle, C.G. Salzmann, E. Mayer, J.L. Finney, D.T. Bowron, Phys. Chem. Chem. Phys. 13, 8783 (2011)

15. P. Ball, $\mathrm{H}_{2} \mathrm{O}:$ A Biography of Water (Hachette, UK, 1999)

16. P. Jenniskens, D. Blake, ApJ 473, 1104 (1996)

17. K. Lodders, ApJ 591, 1220 (2003)

18. K. Wada, H. Tanaka, T. Suyama, H. Kimura, T. Yamamoto, ApJ 677, 1296 (2008)

19. B. Gundlach, Y. Skorov, J. Blum, Icarus 213, 710 (2011)

20. B. Gundlach, S. Kilias, E. Beitz, J. Blum, Icarus 214, 717 (2011)

21. K. Ros, A. Johansen, Astr. \& Astrophys. 552, A137 (2013)

22. T. Koop, Proceedings of the International School of Physics Enrico Fermi (Water: Fundamentals as the Basis for Understanding the Environment and Promoting Technology) 187, 45 (2015)

23. E. Mayer, J. Appl. Phys. 58, 663 (1985)

24. E. Burton, W. Oliver, Nature 135, 505 (1935)

25. M. Nič, J. Jirát, B. Košata, A. Jenkins, A. McNaught, eds., IUPAC Compendium of Chemical Terminology (IUPAC, 2009)

26. O. Mishima, L.D. Calvert, E. Whalley, Nature 310, 393 (1984)

27. J.S. Tse, D.D. Klug, C.A. Tulk, I. Swainson, E.C. Svensson, C.K. Loong, V. Shpakov, V.R. Belosludov, R.V. Belosludov, Y. Kawazoe, Nature 400, 647 (1999)

28. R.J. Nelmes, J.S. Loveday, T. Strässle, C.L. Bull, M. Guthrie, G. Hamel, S. Klotz, Nat. Phys. 2, 414 (2006)

29. K. Winkel, E. Mayer, T. Loerting, J. Phys. Chem. B 115, 14141 (2011)

30. G.N. Ruiz, L.E. Bove, H.R. Corti, T. Loerting, Phys. Chem. Chem. Phys. 16, 18553 (2014)

31. P. Brüggeller, E. Mayer, Nature 288, 569 (1980)

32. O. Mishima, J. Phys. Chem. B 115, 14064 (2011)

33. H. Jones, Rep. Prog. Phys. 36, 1425 (1973)

34. R.C. Ruhl, Mater. Sci. Eng. 1, 313 (1967)

35. T.C. Hansen, P.F. Henry, H.E. Fischer, J. Torregrossa, P. Convert, Meas. Sci. Technol. 19, $034001(2008)$

36. A.-A. Ludl, L.E. Bove, A.M. Saitta, M. Salanne, T. Hansen, C.L. Bull, R. Gaal, S. Klotz, Phys. Chem. Chem. Phys. 17, 14054 (2015)

37. J. Rodríguez-Carvajal, Physica B 192, 55 (1993)

38. T. Roisnel, J. Rodríguez-Carvajal, WinPLOTR: a windows tool for powder diffraction pattern analysis, in, Materials Science Forum (Transtec Publications; 1999, 2001), Vol. 378, p. 118

39. W.F. Kuhs, M.S. Lehmann, Water Sci. Rev. 2, 1 (1986)

40. B. Klewe, B. Pedersen, Acta Crystallogr., Sect. B: Crystallogr. Crystal. Chem. 30, 2363 (1974)

41. K. Muldrew, L.E. McGann, Ch. 6 phase diagrams (1997), http://people.ucalgary.ca/ kmuldrew/cryo_course/cryo_chap6_1.html

42. H. Landolt, R. Börnstein, H. Borchers, W. Helling, E. Schmidt, Zahlenwerte und Funktionen aus Physik, Chemie, Astronomie, Geophysik und Technik: Technik. 2. Teil. [Stoffwerte und Verhalten von metallischen Werkstoffen.] Bandteil b. Sinterwerkstoffe. Schwermetalle (ohne Sonderwerkstoffe) (Springer-Verlag, 1964)

43. T. Williams, C. Kelley et al., Gnuplot 4.6: an interactive plotting program, http://gnuplot. sourceforge.net/ (2014) 
44. A.A. Ludl, High pressure salty ice - exploring the phase diagram of electrolyte solutions in extreme conditions (2015)

45. L.E. Bove, S. Klotz, J. Philippe, A. Saitta, Phys. Rev. Lett. 106, 125701 (2011)

46. L.E. Bove, C. Dreyfus, A. Polian, B. Bonello, I. Malfanti, A. Taschin, R. Torre, R.M. Pick, J. Chem. Phys. 134, 034514 (2011)

47. A.-A. Ludl, L.E. Bove, D. Corradini, A.M. Saitta, M. Salanne, C.L. Bull, S. Klotz, Phys. Chem. Chem. Phys. 19, 1875 (2017) 